\title{
Roles of topoisomerase IV and DNA gyrase in DNA unlinking during replication in Escherichia coli
}

\author{
E. Lynn Zechiedrich and Nicholas R. Cozzarelli \\ Department of Molecular and Cell Biology, University of California, Berkeley, California 94720-3204 USA
}

\begin{abstract}
For a cell to complete DNA replication, every link between the Watson-Crick strands must be removed by topoisomerases. Previously, we reported that the inhibition of topoisomerase IV (topo IV) leads to the accumulation of catenated plasmid replicons to a steady-state level of $\sim 10 \%$. Using pulse labeling with $\left[{ }^{3} \mathrm{H}\right]$ thymidine in Escherichia coli, we have found that in the absence of topo IV activity, nearly all newly synthesized plasmid DNA is catenated. Pulse-chase protocols revealed that catenanes are metabolized even in the absence of topo IV and that the residual turnover is carried out by DNA gyrase at a rate of $\sim 0.01 / \mathrm{sec}$. Using extremely short pulse-labeling times, we identified significant amounts of replication catenanes in wild-type cells. The rate of catenane unlinking in wild-type cells by the combined activities of topo IV and DNA gyrase was $\sim 1 /$ sec. Therefore, gyrase is 100 -fold less efficient than topo IV in plasmid replicon decatenation in vivo. This may explain why a fully functional gyrase cannot prevent the catenation of newly synthesized plasmid DNA and the partition phenotype of topo IV mutants. We conclude that catenanes are kinetic intermediates in DNA replication and that the essential role of topo IV is to unlink daughter replicons.
\end{abstract}

[Key Words: Topoisomerase IV; DNA gyrase; catenane; DNA replication; topology; quinolones]

Received August 4, 1995; revised version accepted October 6, 1995.

Completion of DNA replication requires that the number of links between the Watson-Crick strands of the interwound duplex be reduced to zero /Watson and Crick 1953; Cozzarelli 1992). The DNA unlinking must be very rapid to keep up with the replication fork and yet thorough enough that no link remains at the end of the process. A model for how this might occur is shown in Figure 1 . We have diagrammed it for a simple circular chromosome, but similar considerations apply to all chromosomes, because it is likely that they are separated into topologically distinct domains (for review, see Drlica 1987; Ullsperger et al. 1995). When the replication fork progresses through double-stranded DNA, the unwinding of the DNA strands results in compensatory overwindings, $(+)$ supercoils, in front of the fork that must be removed for the fork movement to continue. Unless the replicated region is topologically contained, the $(+)$ supercoils should be able to diffuse between the replicated and unreplicated regions of DNA /Champoux and Been 1980). The resulting proposed topological intermediates are equivalent and can be interconverted as denoted by the double arrow in Figure 1B. Because the supercoils behind the replication fork would be similar structurally to catenanes of nicked molecules, we call them "precatenanes."

We have suggested that where the supercoils are located, and thus removed, depends on the stage of DNA replication (Ullsperger et al. 1995). We roughly define three stages during replication: (1) early (Fig. 1A), when the unreplicated region is large and DNA unlinking occurs preferentially in front of the fork; (2) intermediate (Fig. 1B), when the unreplicated and replicated regions are similar in size and unlinking may take place both in front of and behind the fork; and (3) terminal (Fig. 1C), when the last few turns of the helix are denatured and the final parental interlinks plus any unlinked nodes from the previous stages are converted into true catenane nodes that must be unlinked.

Linkage removal is carried out by DNA topoisomerases. These enzymes alter the topology of the DNA by passing an intact DNA segment either through transient single-stranded breaks (type 1) or through doublestranded breaks (type 2) (for review, see Osheroff et al. 1991; Wang 1991). There are four principal topoisomerases in Escherichia coli and its well-characterized relatives: I ( $\omega)$, II (gyrase), III, and IV. Topo isomerase I (topo I) and topo III are type-1 enzymes. Mutations in top $A$, the gene that encodes topo I, allow viability only with compensatory mutations elsewhere (DiNardo et al. 1982; Raji et al. 1985). Topo III can function to unlink replicons in vitro (Hiasa et al. 1994), but is dispensable in vivo (DiGate and Marians 1988). DNA gyrase and topo IV are type- 2 enzymes. The genes for the two gyrase subunits are $\operatorname{gyr} A$, which is homologous to parC of topo IV, and 

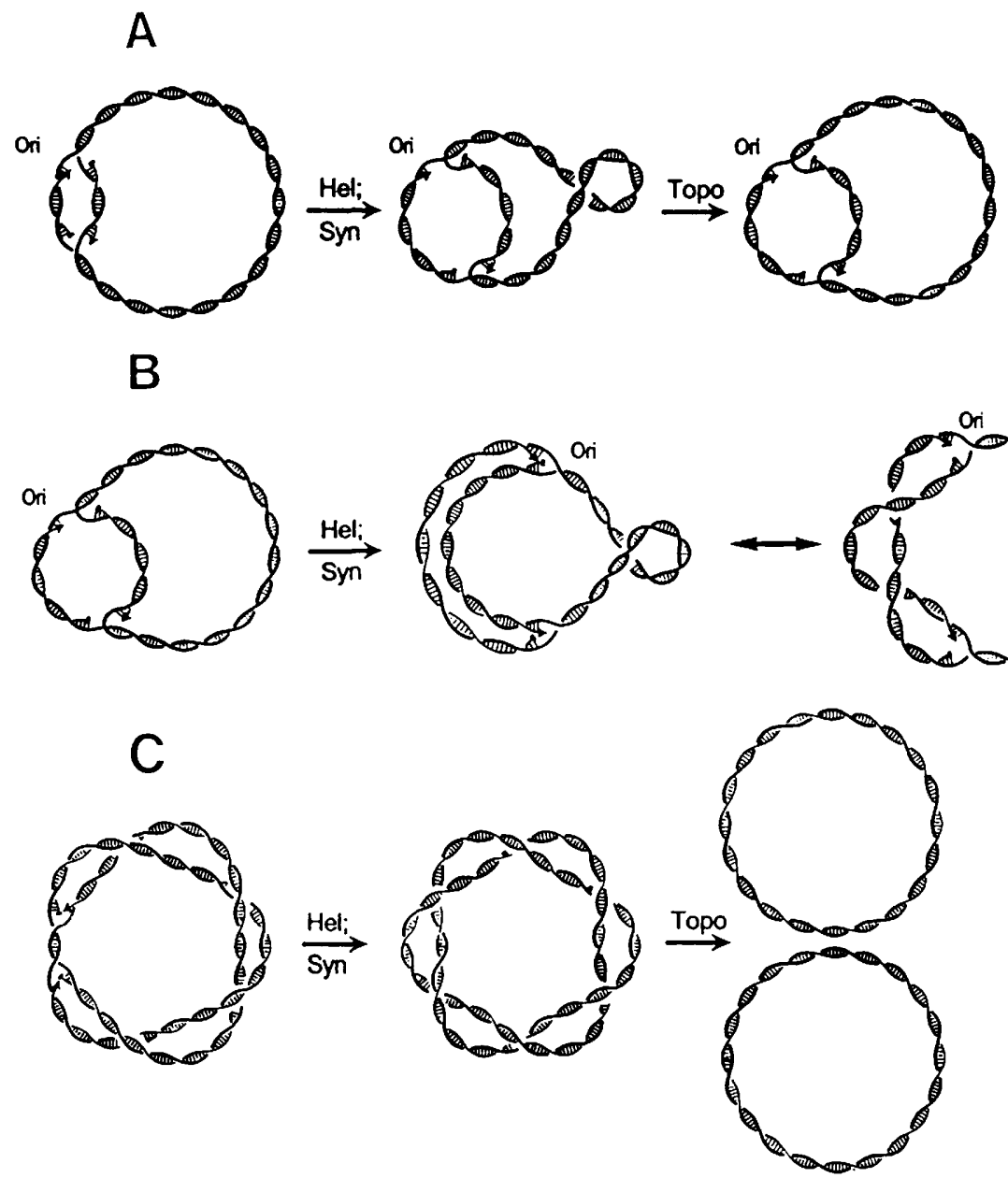

Figure 1. Model for DNA unlinking during replication. We distinguish three stages in DNA replication. $(A)$ Early. Helicase (Hel) action, DNA synthesis (Syn), and associated factors have progressed only a short way from the replication origin (Ori). The unreplicated region is large, and DNA unlinking by a topoisomerase (Topo) occurs primarily in front of the fork. $(B)$ Intermediate. When the unreplicated and replicated regions are similar in size, unlinking may take place both in front of and behind the fork. The interconvertability of the topologically equivalent intermediates is denoted by the double arrow. $|C|$ Terminal. Upon denaturation of the last few turns of the helix, these turns plus any interlinks remaining from the previous stages are converted into true catenane nodes between the daughter replicons. These are unlinked by a topoisomerase. For simplicity, unidirectional replication is depicted. Topologically, bidirectional replication should be the same. Implicit in this model is that replication initiation and elongation must be fully functional to yield catenanes.

gyrB, which is homologous to parE of topo IV (Kato et al. 1990; Luttinger et al. 1991; Springer and Schmid 1993). The genes for topo IV are so named because in temperature-sensitive (ts) mutants the chromosome fails to partition (par) at a nonpermissive temperature. The gyrase and topo IV genes are not interchangeable, although overexpression of gyr $A$ and $g y r B$ can rescue partially topo IV $^{\text {ts }}$ mutants at the nonpermissive temperature (Kato et al. 1992). Mutations in any of the four genes that encode the type-2 enzymes can be lethal (Kreuzer and Cozzarelli 1979; Orr et al. 1979; Filutowicz and Jonczyk 1983; Kato et al. 1988; Schmid 1990).

As depicted in Figure 1, a topoisomerase is needed in all stages of replication unlinking. Which topoisomerase(s) acts at each stage? The biochemical and genetic data demonstrate that gyrase acts by introducing $(-\mid$ supercoils into the unreplicated DNA (Baker et al. 1986; Wang 1991). Before the discovery of topo IV, gyrase was also proposed to unlink DNA at the later stages of replication. In particular, three studies implicated DNA gyrase as a major decatenase in bacteria. First, gyrase decatenates both intact (closed circular) and interrupted (nicked or gapped) plasmid catenanes in vitro (Kreuzer and Cozzarelli 1980; Marians 1987; Hiasa et al. 1994). The type-1 enzymes are restricted to interrupted catenane substrates. Thus, a type-1 enzyme could not unlink catenanes in the terminal stage of unlinking. Second, doublet nucleoids accumulated in a ts gyrase mutant at the nonpermissive temperature that, when purified, segregated into singlets with addition of excess 
DNA gyrase (Steck and Drlica 1984). Third, the addition of drugs, whose only known target at that time was gyrase, blocked the unlinking of catenanes generated by recombination in vivo (Bliska and Cozzarelli 1987). These results, however, do not prove that gyrase is the sole or even primary decatenase of the products of replication in vivo.

We discovered that ts mutations in parC or parE, which render the cell defective in chromosomal partitioning (Kato et al. 1988; Schmid 1990), lead to the accumulation of catenated plasmids at the nonpermissive temperature (Adams et al. 1992). Topological analysis proved that the catenanes were derived from replication (Adams et al. 1992). Replication catenanes had never been observed after inhibition of any of the other three topoisomerases in any bacteria. Therefore, we suggested that topo IV was the most important replicon decatenase of the cell (Adams et al. 1992). A problem with this conclusion was that a steady-state level of $\leqslant 10 \%$ of the total plasmid DNA was catenated in the topo IV mutants at the nonpermissive temperature; for some plasmids the level of accumulated catenanes was only a few percent. Furthermore, even at the nonpermissive temperature, the catenanes were metabolized (Adams et al. 1992). Therefore, we could not prove that catenanes were normal intermediates in DNA replication or that they accumulated because they are normally substrates for topo IV.

In this report we show that DNA catenanes are kinetic intermediates in plasmid replication. In the absence of topo IV activity, nearly all newly replicated DNA is catenated. These catenanes are slowly metabolized by DNA gyrase. We measured the rate of topo IV unlinking in wild-type cells to be $\sim 100$-fold faster than that of gyrase. This can explain why gyrase is unable to prevent catenane accumulation, the partition defect, and ultimately, death in topo IV mutants.

\section{Results}

Nearly all newly replicated plasmid DNA is catenated in topo IV mutants

Because the steady-state level of catenated plasmid DNA in topo IV mutants was $\leqslant 10 \%$, it was possible that only a small fraction of DNA replication proceeds through catenated intermediates. Alternatively, catenanes may be kinetic intermediates in replication, but topo IV has only a minor role in decatenation. A third possibility is that catenanes are intermediates that are usually metabolized by topo IV, but that some residual activity in the parC or parE mutants slowly unlinks the majority of the catenanes.

To distinguish among these alternatives, we pulse-labeled replicating pBR322 plasmid DNA. This allowed us to examine the presteady-state level of plasmid catenation. The mutant or wild-type cells were pulse labeled for $0.5,3$, or $5 \mathrm{~min}$ after $30 \mathrm{~min}$ at $43^{\circ} \mathrm{C}$. Upon electrophoresis of isolated plasmid DNA on high resolution gels, supercoiled (sc) catenanes run between the sc dimer and nicked monomer bands (Fig. 2A,B). For a 0.5-min pulse, $86 \%$ of the label was in the catenane bands for the topo IV mutants (lanes 1,7 ). For a 3 -min pulse, $45 \%$ of the label was in the catenane bands (lanes 2,8). After a 5 -min pulse time, $30 \%$ of the label was in the catenane bands (lanes 3,9). Cells incubated at the nonpermissive temperature for 15 to 180 min gave the same results, although the amount of label incorporated was much reduced after $120 \mathrm{~min}$ (data not shown). When the isolated plasmid DNA was nicked, the amount of label in the resultant catenane ladder corresponded to the amount of label in the sc catenane band shown in Figure $2 \mathrm{~A}$ (e.g., Fig. $6 \mathrm{~B}$ is from the same sample in lane 3 that had been DNase I nicked). For these pulse-labeling times, $<1 \%$ of the plasmid was catenated in the wildtype topo IV cells.

The results from 18 pulse-labeling experiments were quantified (Fig. 2C). The amount of labeled DNA that was catenated decreased with increased pulse time. Extrapolation to a theoretical infinitesimal pulse reveals that nearly all newly replicated DNA is in the catenated form. Results were the same for all the $\operatorname{par}^{\text {ts }}$ and $\operatorname{par}^{\text {ts }}$ mutant strains tested (Fig. 2C). Therefore, catenanes are kinetic replication intermediates in topo IV mutants. This implies that the removal of catenane interlocks in wild-type strains must be carried out predominantly by topo IV. The low amount of catenanes observed in our previous steady-state experiments results entirely from residual turnover in the topo IV mutants.

\section{Catenanes are slowly metabolized by a type-2 topoisomerase in topo IV mutants}

At the nonpermissive temperature for topo IV mutants, some activity was metabolizing the catenane intermediates. Pulse-chase protocols enabled us to study this turnover. Exponential cultures of topo IV mutant cells were shifted to $43^{\circ} \mathrm{C}$ for $30 \mathrm{~min}$ and pulse-labeled with [ $\left.{ }^{3} \mathrm{H}\right]$ thymidine for 1-3 min. A 4000 -fold excess of cold thymidine (chase) was added to stop incorporation of label. If the chase was added before the pulse, negligible incorporation $(<1 \%)$ was seen in chromosomal or plasmid DNA (data not shown).

To measure the turnover rate of catenanes, plasmid catenation was examined at various times after the initiation of the chase. Plasmids were isolated, nicked with DNase I and analyzed by high resolution gel electrophoresis. An autoradiograph from a typical experiment is shown in Figure $3 \mathrm{~A}$. At time 0 , before the chase and after a $1.5-\mathrm{min}$ pulse, the catenanes were $53 \%$ of the total amount of label and the mean catenane node number was 12. After a 4-min chase, the catenane bands represented $29 \%$ of the label and the mean catenane node number decreased to 8 . After a $10-\mathrm{min}$ chase, the catenanes were $7 \%$ of the total amount of label and the mean catenane node number was 8 . After $30 \mathrm{~min}$, only $4 \%$ of the label was in the catenane bands and the mean node number was 6 . Pulse-chase experiments, as shown with the $\operatorname{par}^{\mathrm{ts}}$ thy $A$ mutant in Figure $3 \mathrm{~A}$, were repeated with the par $E^{\text {ts }}$ mutant. The data for the fraction of cat- 
Figure 2. Proportion of catenanes in pulse-labeled pBR322 plasmid DNA. Cells were grown to mid-log phase, shifted to $43^{\circ} \mathrm{C}$ for $30 \mathrm{~min}$, and pulse labeled with $\left[{ }^{3} \mathrm{H}\right]$ thymidine. Cells were lysed and plasmid DNA was isolated. $(A)$ An autoradiograph of a high-resolution agarose gel. The first lane in each set of three represents a $0.5-\mathrm{min}$ pulse time, the second a $3-\mathrm{min}$ pulse time, and the third a 5-min pulse time. (Lanes 1-3) par $E^{\text {ts }}$ (ParE10); (lanes 4-6) parE ${ }^{\mathrm{wt}}$ (W3110); (lanes 7-9) parC p $^{\mathrm{ts}}$ (ParCl215); (lanes 10-12) parC ${ }^{\text {wt }}$ (C600). The positions of $(-\mid$ supercoiled $(\mathrm{sc})$, nicked, and linear monomer and dimer are shown. The sc catenanes run between nicked monomer and sc dimer as indicated. $(B)$ An underexposure of the top first six lanes in $A$. The supercoiled catenane bands can be more clearly seen. $(C)$ Plotted is the percentage of labeled plasmid DNA that is catenated as a function of duration of pulse. Experiments were carried out once for the $\operatorname{parC}^{\text {ts }}(\square)$, eight times for the par $C^{\mathrm{ts}}$ thy $A(\mathbf{O})$, and nine times for the par $E^{\mathrm{ts}}(O) \mathrm{mu}$ tants. Because the incorporation of $\left[{ }^{3} \mathrm{H}\right]$ thymidine was linear for only $5 \mathrm{~min}$ (see Materials and methods), we did not carry out longer pulse times. Thus, the data for the 15 -min time point are from the steady-state catenane level after a $15-$ to 120 -min incubation at the nonpermissive temperature. The line represents a first-order exponential decay.

enated DNA from 15 separate experiments were averaged, and the result is shown on a semilogarithmic plot (Fig. 3B). The best fit first-order exponential decay curve gives a catenane turnover rate of $0.01 / \mathrm{sec}$ (see Materials and methods for calculation) and a catenane half-life of $3.2 \mathrm{~min}$ (Fig. 3B, arrow).

There are two likely ways that the cell could remove the catenanes at the nonpermissive temperature for the topo IV mutants. The cell could recognize the catenanes as aberrant replication products and degrade them. If this were the case, the label in the catenanes would chase into linearized and ultimately degraded material. Alternatively, a topoisomerase could decatenate them, generating labeled circular monomers with increasing time of chase.

With chase, circular monomers appeared as catenanes disappeared in a fashion expected for a product-precursor relationship (Fig. 4). The total amount of labeled plasmid present during the 30 -min chase did not vary significantly. No linear or degraded DNA was seen beneath

B
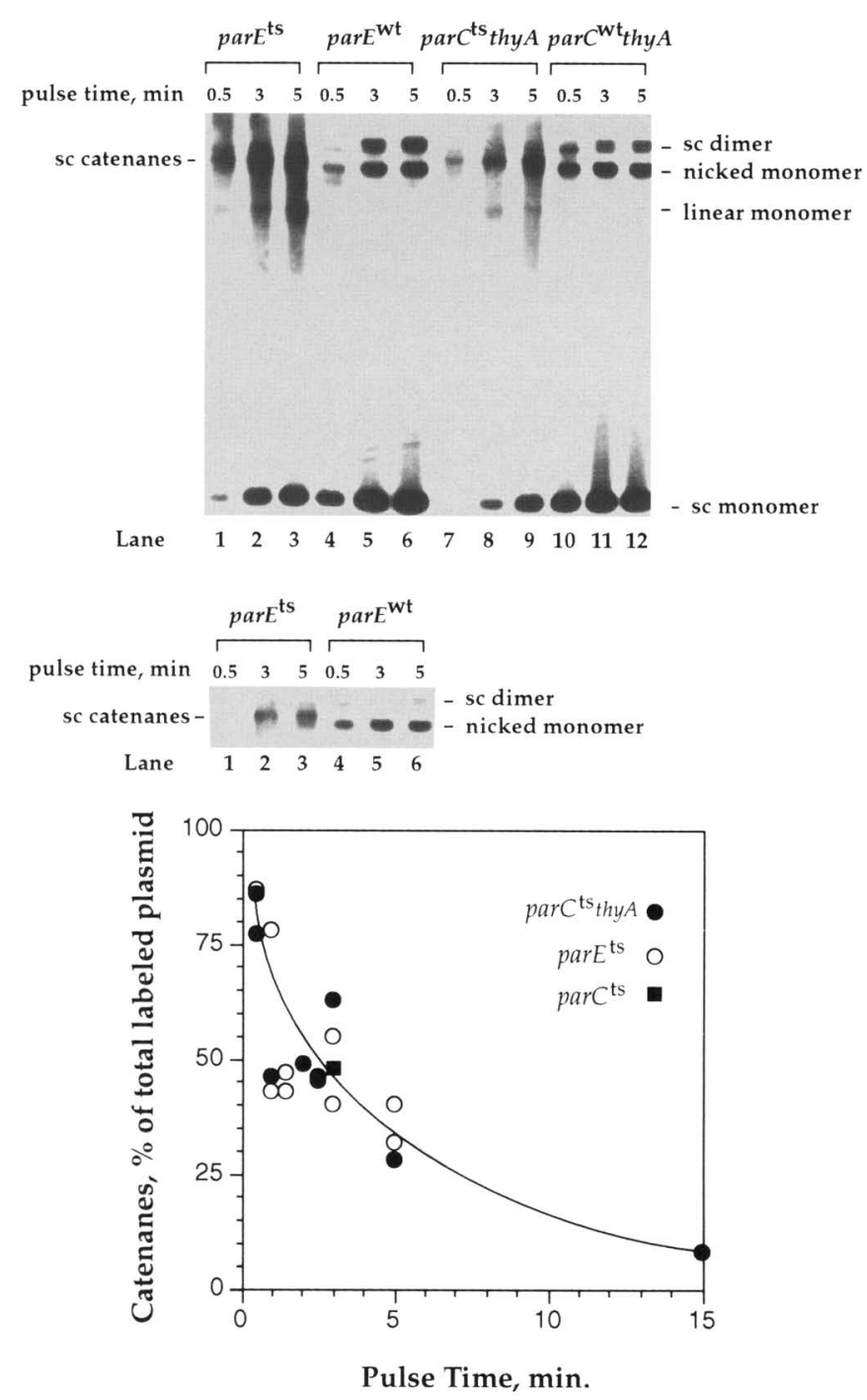

the monomer bands in any of the 15 experiments using par $C^{\text {ts }}$ thy $A$, parE $E^{\text {ts }}$, or parC $C^{\text {ts }}$ mutant cells. Gel electrophoresis of plasmids that were not nicked showed that the label turns over into sc monomer. Therefore, topo IV mutant cells convert sc catenanes into sc monomer plasmids by a type 2 topoisomerase.

\section{DNA gyrase is important for catenane turnover in topo IV mutants}

What is the enzyme responsible for unlinking catenanes in the topo IV mutants at the nonpermissive temperature? Because $\sim 90 \%$ of the labeled catenanes was supercoiled, and thus closed circular, a type-2 topoisomerase is required to unlink them. DNA gyrase and topo IV are the only known type- 2 enzymes in bacteria. We could not eliminate topo IV as a candidate, because there could be residual activity in the mutants. To distinguish which topoisomerase is responsible, we took advantage of the sensitivity of gyrase to a class of antibiotic drugs, the 
A

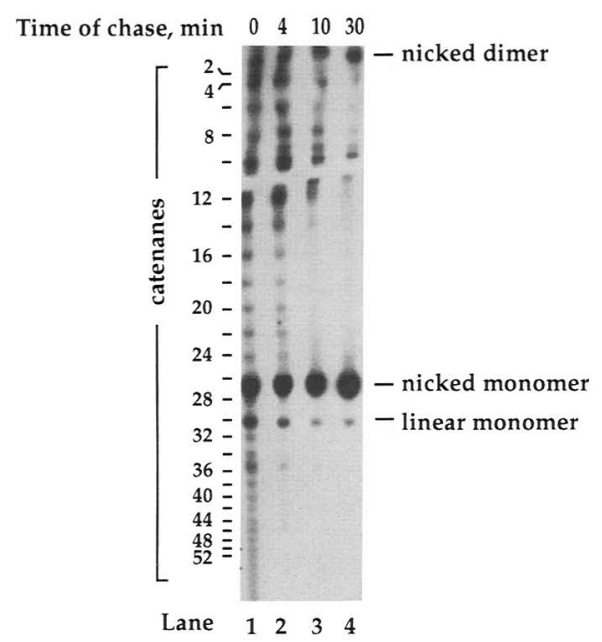

B

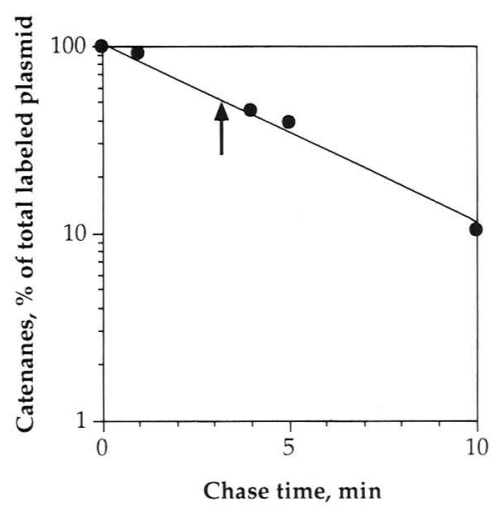

Figure 3. Catenane turnover in topo IV mutants. Cells were grown to mid-log phase, shifted to $43^{\circ} \mathrm{C}$ for $30 \mathrm{~min}$, and pulse labeled with $\left[{ }^{3} \mathrm{H}\right]$ thymidine. At time 0 , a 4000 -fold excess of unlabeled thymidine (chase) was added. Plasmid topology was examined at various times after the chase. $|A|$ Autoradiograph of DNase I-nicked plasmids run on a high-resolution gel. Time 0 (lane 1) shows the labeled DNA after a 1.5- min pulse in the parE ts mutant. (Lane 2) After a 4-min chase; (lane 3) after a 10-min chase; (lane 4) after a $30 \mathrm{~min}$ chase. Catenanes are seen as a ladder ranging in complexity from 2 to $>52$ nodes. The positions of nicked monomer, linear monomer, and nicked dimer are shown. Results were the same for six different experiments with par $C^{\text {wt }}$ thy $A$, one with parC $C^{t s}$, and eight with parE $E^{\text {ts }}$ cells. $(B)$ Data from experiments were averaged, normalized to $100 \%$, and graphed as a semilogarithmic plot. The data for both mutants fit well to a first-order exponential decay with a catenane turnover rate of $0.01 / \mathrm{sec}$ (see Materials and methods for calculation/ and a catenane half-life of $3.2 \mathrm{~min}$, as indicated by the arrow.

quinolones (Andoh et al. 1993). However, topo IV is also inhibited by quinolones in vitro (Kato et al. 1992; Peng and Marians 1993a; Khodursky et al. 1995) and has been shown to be a secondary target in vivo (Khodursky et al. 1995). Therefore, we constructed strains that contained par $E^{\text {ts }}$ and either a quinolone-resistant $\left(g y r A^{\mathrm{r}}\right)$ or a wildtype gyrase (gyrA $A^{\mathrm{wt}}$ ) allele (Yoshida et al. 1988). If the addition of the quinolone norfloxacin blocked catenane turnover in the par $E^{\text {ts }} g y r A^{\text {wt }}$, but not in the par $E^{\text {ts }} g y r A^{\mathrm{r}}$ strain, then we could be confident that the drug was inhibiting only gyrase and that gyrase was responsible for the turnover.

$\operatorname{par}^{\mathrm{ts}} g y r A^{\mathrm{r}}$ and $\operatorname{par} E^{\mathrm{ts}} g y r A^{\mathrm{wt}}$ strains were pulse labeled with $\left[{ }^{3} \mathrm{H}\right]$ thymidine for $1 \mathrm{~min}$ (Fig. 5A, lanes 1,4$)$, and chased in the presence (lanes 3,6) or absence (lanes $2,5)$ of norfloxacin for $30 \mathrm{~min}$. The amount of label incorporated into total plasmid DNA and the turnover of the catenanes in the absence of drug was the same in both strains. The results are depicted graphically (Fig. 5B). A concentration of $5 \mu \mathrm{g} / \mathrm{ml}$ of norfloxacin blocked catenane turnover completely in the par $E^{\text {ts }} g y r A^{\text {wt }}$ strain. In contrast, $5 \mu \mathrm{g} / \mathrm{ml}$ of norfloxacin had little effect on catenane turnover in the $\operatorname{par}^{\mathrm{ts}} g y r A^{\mathrm{r}}$ strain. We conclude that DNA gyrase is responsible for decatenation of plasmid replicons in the topo IV mutants.

\section{Catenane turnover in wild-type cells}

We have shown that DNA gyrase unlinks replication intermediates at a slow rate, resulting in a half-life for these plasmid catenanes of $\sim 3 \mathrm{~min}$ in topo IV mutants. Clearly, the decatenation rate of topo IV must be much faster than this because only small amounts of catenanes are seen in wild-type cells. To quantify this rate, we carried out labeling experiments with short pulse times. To keep the protocol consistent with that of the mutant strains and to control for potential temperature effects, we grew wild-type cells at $30^{\circ} \mathrm{C}$ and carried out pulse labeling at $43^{\circ} \mathrm{C}$. Labeling times were 5,20 , or $60 \mathrm{sec}$. To stop replication rapidly after these short pulse times, we immersed the cells in liquid nitrogen. After thawing the cells on ice, we isolated plasmids by alkaline lysis.

Figure 6A shows a densitometric scan of an autoradiograph of a high-resolution gel of nicked plasmid DNA after a 5 -sec pulse. A significant portion of the newly replicated plasmid was catenated, and a spectrum of ca-

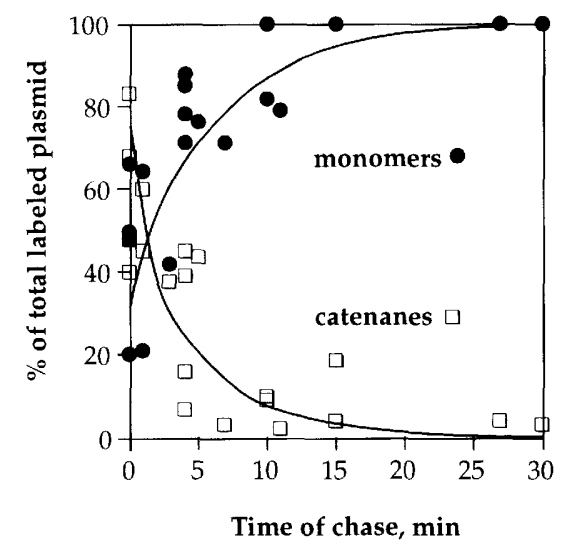

Figure 4. Fate of labeled catenanes during chase. The experiment was as described in the legend to Fig. 3. Plotted is the amount of labeled DNA in monomers and catenanes with time of chase. The appearance of labeled sc monomers $(\mathbf{O})$ coincided with the disappearance of labeled catenanes $(\square)$. The lines represent first-order exponential fit to the data. 
A

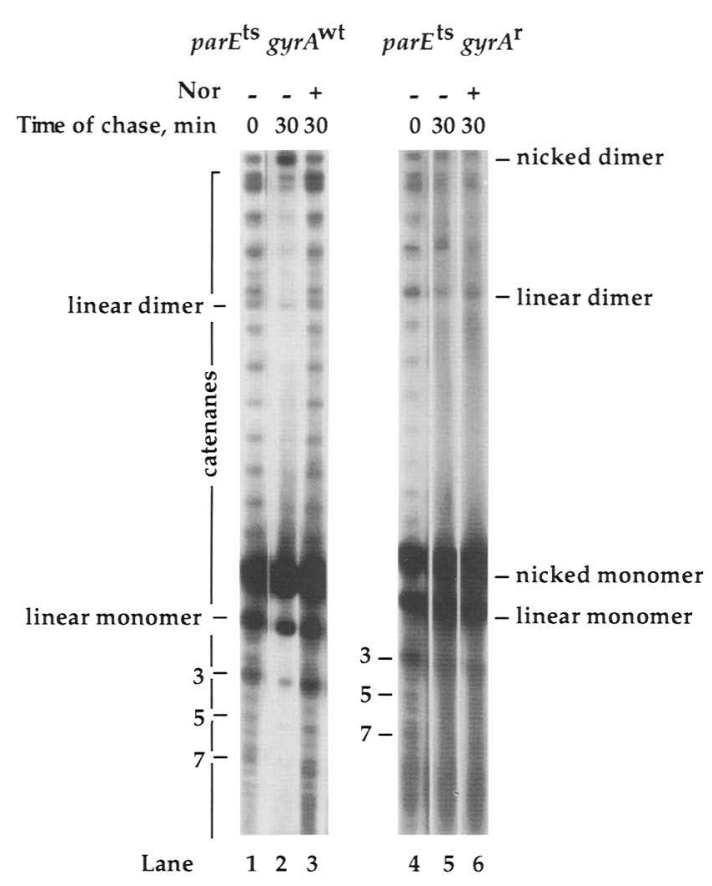

B

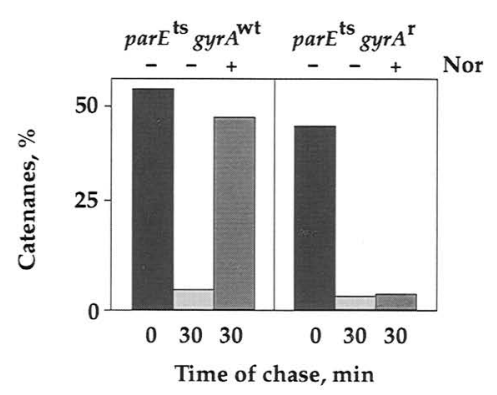

Figure 5. Effect of norfloxacin on catenane turnover in a topo IV mutant. The pulse-chase experiment was as described for Fig. 3 , except that for half of the samples, norfloxacin (Nor) was added with the chase. $(A)$ An autoradiograph of a high-resolution gel. Lanes 1-3 are from the par $E^{\text {ts }} g y r A^{\text {wt }}$ mutant; lanes 4-6 are from the parE $E^{\text {ts }} g y r A^{\mathrm{r}}$ mutant. Time 0 (lanes 1,4 ) shows the labeled DNA after a 2-min pulse. Chase alone (lanes 2,5) or chase plus $5 \mu \mathrm{g} / \mathrm{ml}$ of norfloxacin (lanes 3,6 ) was for $30 \mathrm{~min}$. The positions of nicked monomer, linear monomer, and nicked dimer are shown. There are small amounts of knotted replication product present with three, five, and seven nodes. $(B)$ Fraction of total label in catenanes in $\operatorname{par}^{\mathrm{ts}} \mathrm{gyr} A^{\mathrm{wt}}$ or $\operatorname{par}^{\mathrm{ts}} \mathrm{gyr} A^{\mathrm{r}}$ cells. The percentage of labeled catenanes from $A$ is shown. The results were qualitatively identical for two additional experiments (not shown).

tenanes was revealed, containing from 2 to 16 nodes. As with the topo IV mutants, the amount of replicated plasmid that was catenated decreased with increased time of pulse (Fig. 7). One ambiguity in quantifying these results is whether to include the two-noded catenanes, because they can arise from cellular processes other than DNA replication (Wasserman and Cozzarelli 1986). In the plot shown in Figure 7, the two-noded catenane was included, but if we omit it, the overall conclusions are unchanged. From the fraction of catenanes as a function of pulse time, we calculated the catenane turnover rate in wild-type cells by the combined activities of topo IV and gyrase to be $\sim 1 / \mathrm{sec}$ (Fig. 7 ; see Materials and methods for calculation). The data from the topo IV mutants are shown for comparison.

When compared with a densitometric scan of the pattern of labeled catenanes from the par $E^{\text {ts }}$ mutant at a comparable level (25\%) (Fig. 6B), the scan of the wildtype catenanes after a 5-sec pulse (Fig. 6A) is very similar except for the excess of two-noded catenanes. Therefore, mutations in topo IV increase only the half-life of replication catenanes, not their complexity. We conclude that catenanes are kinetic intermediates in plasmid DNA replication that are unlinked by both type 2 topoisomerases in bacteria. Topo IV is the major decatenase with a rate of $\sim 1$ /sec and DNA gyrase contributes with a rate of $\sim 0.01 / \mathrm{sec}$.

\section{Discussion}

We have shown that nearly all newly replicated plasmids are catenated in parC $C^{\text {ts }}$ or parE $E^{t s}$ strains at the nonpermissive temperature. Very brief pulse labeling in wildtype cells revealed significant levels of catenanes with complexity similar to that seen in the mutants (Figs. 6 and 7|. Because of turnover, the fraction of labeled plasmid DNA that was catenated in both mutant and wildtype strains depended on the length of the pulse time (Figs. 2 and 6). From the plot in Figure 2C, we can extrapolate that for a 1 - or 2 -sec pulse, $\geqslant 90 \%$ of the plasmid DNA would be catenated in the absence of topo IV. We draw two important conclusions from these results: (1) For $\geqslant 90 \%$ of plasmid DNA molecules, catenanes are kinetic intermediates in plasmid replication; and (2) topo IV is the principal decatenase of the bacterial cell. An alternative replication pathway could involve only $\leqslant 10 \%$ of the DNA. Although this study was carried out exclusively with the plasmid pBR322, our other work with topo IV-mediated unlinking showed that results were similar with different plasmids (Adams et al. 1992; Khodursky et al. 1995).

The evidence strongly favors a critical role for topo IV in decatenation at the terminal stage of replication rather than precatenane removal at an intermediate stage (Fig. 1). There must not be a strict requirement for precatenane unlinking by topo IV during replication elongation or catenanes would not accumulate with topo IV inactivation. Moreover, no increase in the amount $(\leqslant 10 \%)$ of other replication intermediates was seen when topo IV was inactivated either by mutation (this study; Adams et al. 1992) or by quinolones (Khodursky et al. 1995). One concern would be that such intermediates might be lost in the plasmid isolation protocol. However, the amount of radiolabel recovered in plasmid DNA was the same for the wild-type and mutant strains (Fig. 2A) and we have used several different DNA isolation techniques with identical results. Finally, up to $25 \%$ of newly replicated plasmid DNA was catenated in wild-type cells and the mean number of catenane nodes 

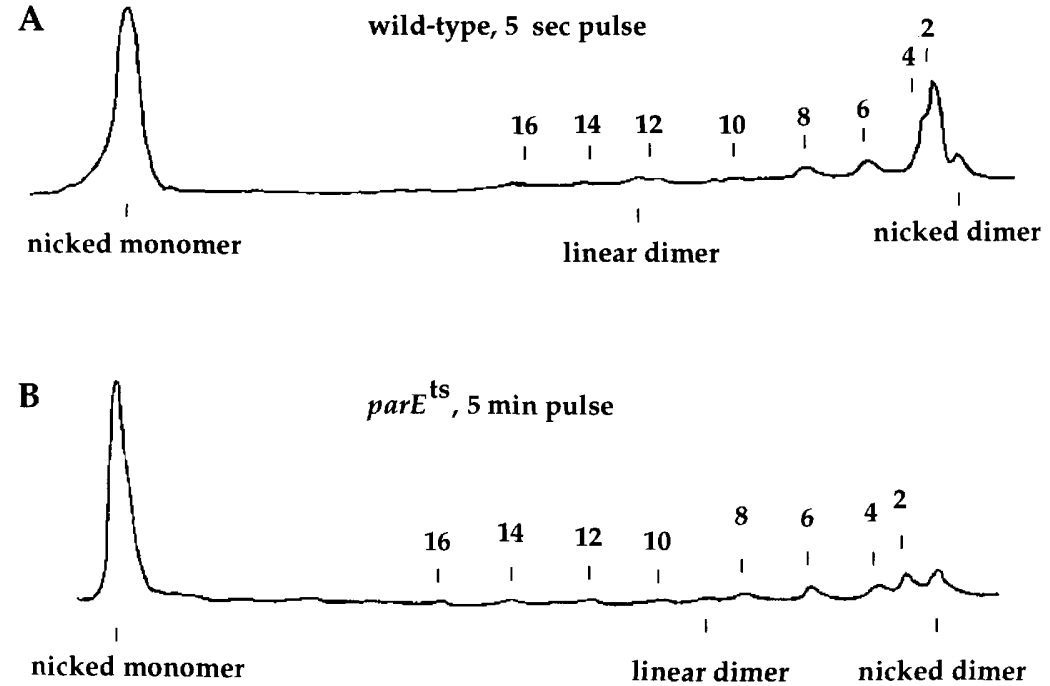

Figure 6. Comparison of catenane profiles in wild-type and parE ${ }^{\text {ts }}$ mutant cells. The protocol was as described in the legend to Fig. 2 except that the pulse was for $5 \mathrm{sec}$ for the wild-type strain and the cells were immersed in liquid nitrogen to stop the incorporation of label. Densitometric scans of autoradiographs of high-resolution gels are shown. $(A)$ wild-type (C600) cells labeled for 5 sec. $(B)$ parE ${ }^{\text {ts }}$ (ParE 10) labeled for $5 \mathrm{~min}$. This is the same sample of DNA shown without DNase I treatment in the supercoiled plasmid profile of Fig. 2A, lane 3. Positions of nicked monomer, nicked dimer, and linear dimer are indicated. Catenanes are designated by node number. The amount of DNA that was catenated was $\sim 25 \%$ for both strains. was similar in wild-type and topo IV mutant cells for the same level of catenation (Fig. 6). Thus, if topo IV has a role in replication unlinking in the early and intermediate stages, that role can be taken over by another topoisomerase, perhaps gyrase.

We and other investigators have argued on topological grounds that it is difficult to imagine a mechanism by which the linking number is reduced to zero precisely

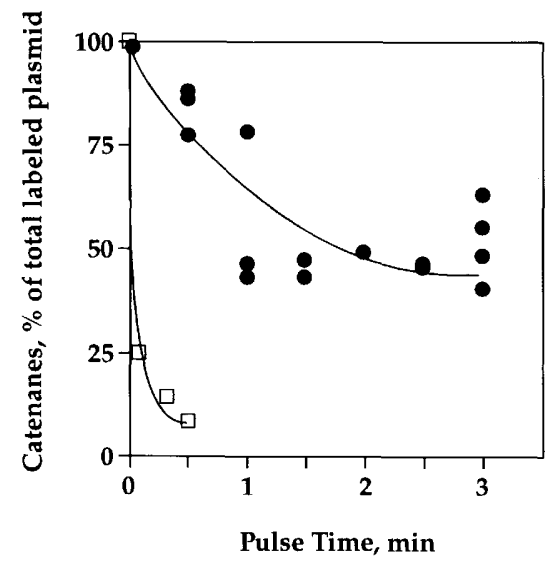

Figure 7. Effect of pulse time on the fraction of labeled DNA in catenanes in wild-type and topo IV mutant cells. The protocol was as described in the legend to Fig. 2 except that the pulse was for 5,20 , or $60 \mathrm{sec}$ for the wild-type cells and the cells were immersed in liquid nitrogen to stop the incorporation of label. The dependence of the amount of labeled catenanes detected as a function of pulse time is graphed for wild-type $(\square)$ cells. In this graph, we assumed that all of the two-noded catenanes arise from replication. Twenty-five percent of the plasmid was catenated for DNA labeled in a $5-\mathrm{sec}$ pulse, $14 \%$ in a 20 -sec pulse, and $8 \%$ for a $60-\mathrm{sec}$ pulse. If we omit the two-noded catenane, the numbers were $8 \%$ for a 5 -sec pulse time, $4 \%$ for a 20 -sec pulse, and 0 for a 60 -sec pulse. The data from Fig. $2 \mathrm{C}$ for the topo $\mathrm{IV}^{\mathrm{ts}}$ mutants $(\mathrm{)})$ are shown for comparison. when DNA replication is completed (Pohl and Roberts 1978, Cozzarelli 1992). However, by chance, some plasmids could have a zero linking number when the last nucleotide is replicated. These would replicate completely without intermediary catenanes (Fields-Berry and DePamphilis 1989) and thus, without the requirement for topo IV in the last stage of unlinking. If we extrapolate the amount expected in this "0-noded" catenane band from the distribution of the rest of the catenanes, we would expect $\sim 10 \%$ of the total labeled plasmid, which is approximately the calculated amount of uncatenated DNA seen in an infinitesimal pulse.

\section{Relative contributions of DNA gyrase and topo IV to DNA unlinking}

In all seven topo IV mutants that we have analyzed, catenanes are slowly unlinked even at the nonpermissive temperature resulting in a steady-state level of catenation of $\sim 10 \%$ (Adams et al. 1992). Here, we find that the addition of low levels of quinolones prevents this residual decatenation. The drug must be targeting gyrase, because in a quinolone-resistant gyrase mutant, catenanes continued to turn over in the presence of drug (Fig. 5). The most straightforward interpretation of these results is that DNA gyrase is able to remove catenane nodes slowly at the end of replication. However, our data do not rule out the possibility of an indirect role for gyrase. Indeed, DNA supercoiling greatly increases both the rate and extent of decatenation by topo IV and DNA gyrase (Vologodskii and Cozzarelli 1993; Hiasa et al. 1994; C.J. Ullsperger and N.R. Cozzarelli, unpubl.). Therefore, DNA gyrase could be supercoiling catenanes so that another type-2 topoisomerase decatenates them. When DNA gyrase was blocked with drug in our experiments, the plasmid DNA was relaxed within 5 min (data not shown|. However, the only other type-2 topoisomerase known in E. coli is topo IV, which is severely compro- 
mised in the mutant strains we used. Furthermore, the simultaneous overexpression of gyr $A$ and gyr $B$ can compensate partially for the conditional lethality of topo IV mutants (Kato et al. 1992), suggesting that in wild-type strains, gyrase might have weak decatenating activity in vivo.

We will assume that the residual decatenation at the nonpermissive temperature in topo IV mutants is carried out directly by DNA gyrase at a rate of $\sim 0.01 / \mathrm{sec}$ (Fig. 3 ). Clearly, this rate is insufficient to prevent nearly all newly replicated plasmid DNA from being catenated at the nonpermissive temperature for topo IV. The rate of decatenation in wild-type cells by a combined effort of topo IV and DNA gyrase is $\sim 1.0 / \mathrm{sec}$ (Fig. 7), 100-fold faster than gyrase alone. Thus, although DNA gyrase is able to carry out decatenation in vitro and in vivo, its primary role in DNA replication is not decatenation.

Why is topo IV so efficient and gyrase so poor at replication decatenation in the cell? A major mechanistic difference between gyrase and topo IV can explain the difference in their activities. DNA gyrase wraps DNA around itself (for review, see Reece and Maxwell 1991). This causes the enzyme to prefer intra- to intermolecular DNA strand passage, consequently precluding it from being an efficient decatenase (Kirchhausen et al. 1985). Topo IV does not wrap DNA (Peng and Marians 1995) and must recognize DNA crossovers as does eukaryotic topo II (Zechiedrich and Osheroff 1990; Roca and Wang $1992,1994)$. Therefore, topo IV should act readily on intermolecular crossovers. In fact, topo IV has up to two orders of magnitude higher specific activity than gyrase for intermolecular unlinking (decatenation)(Peng and Marians 1993b; Hiasa et al. 1994; Hoshino et al. 1994; C. Ullsperger and N.R. Cozzarelli, unpubl.). Conversely, DNA gyrase has a $|-|$ supercoiling activity (intramolecular unlinking) two orders of magnitude higher than the relaxation activity of topo IV (C.J. Ullsperger and N.R. Cozzarelli, unpubl.).

We suggest that gyrase acts in front of the replication fork, when DNA unlinking occurs primarily in the unreplicated region (Fig. 1). Topo IV removes catenane nodes in the terminal stages of replication. If topo IV also acts in the replicated region in the intermediate stages to remove precatenane nodes, this role can be subsumed by gyrase or perhaps topo III. The weak relaxation activity of topo IV does not interfere with the maintenance of negative supercoiling in vivo (this study; Khodursky et al. 1995).

Two previous results need to be reconciled with the enzymatic division of labor described above. In one study Bliska and Cozzarelli (1987) concluded that gyrase decatenated multiply-linked catenanes produced from phage $\lambda$ integrative recombination in $E$. coli. Because topo IV was not yet discovered at that time, this study must be repeated under conditions that clearly differentiate the roles of gyrase and topo IV. Our recent experiments demonstrate that topo IV has a major role in decatenating two-noded catenanes produced from recombination by Tn 3 resolvase in vivo (E.L. Zechiedrich, A. Khodursky, and N.R. Cozzarelli, unpubl.).
The other result that must be reconciled is that gyrase mutants can have a partition defect (Orr et al. 1979; Filutowicz 1980). In one gyrase mutant, dumbbell-shaped nucleoids were found that could be resolved, at least partially, by gyrase in vitro (Steck and Drlica 1984). The in vitro data merely show that gyrase is capable of carrying out decatenation, but the partition defect is more challenging. Perhaps decatenation by gyrase, although slow, is critical for chromosome segregation. Alternatively, it is possible that the mutants of gyrase that show a par phenotype cannot segregate because they do not complete or reinitiate replication. For example, some gyrase mutants could fail late in replication as outlined in Figure 1 , but before the terminal stage where topo IV mutants arrest. It is interesting that the nucleoids from the gyrase mutant used by Steck and Drlica (1984) are smaller than the very enlarged nucleoids from the topo IV mutants (unpublished data). Moreover, plasmids isolated from this mutant at the nonpermissive temperature were not catenated or even replicated /unpublished data). A third possibility is that gyrase mutants can have a partition defect because they reduce supercoiling, which in turn diminishes decatenation by topo IV.

\section{Materials and methods}

\section{Materials}

Norfloxacin, RNase A, and trimethoprim were from Sigma. Pancreatic DNase I from Cooper, proteinase $\mathrm{K}$ from BoehringerMannheim, [methyl- ${ }^{3} \mathrm{H}$ ]thymidine and [methyl- $\mathrm{I}^{\prime}, 2^{\prime}-{ }^{3} \mathrm{H}$ ] thymidine were from Amersham, and $\mathrm{En}^{3} \mathrm{Hance}$ was from DuPont/ New England Nuclear. All other chemicals were of analytical grade from standard commercial sources.

\section{Strains}

Our previous work focused on topo IV mutants of Salmonella typhimurium (Adams et al. 1992). We used E. coli in this study because most studies of DNA replication and topoisomerases have been in this bacterium. The strains used in this study are listed in Table 1. ParC1215 and its wild-type isogenic parent $\mathrm{C} 600$ and ParE10 and its wild-type isogenic parent W3110 were described previously (Kato et al. 1988, 1990). The conditional lethality of ParE 10 cells was much cleaner than that of ParC1215 cells. At $30^{\circ} \mathrm{C}$, the doubling time of ParE 10 cells in Luria broth is roughly that of the isogenic wild-type strain $(20$ $\mathrm{min}$ ), whereas the doubling time of ParC1215 cells is $65 \mathrm{~min}$. At $42^{\circ} \mathrm{C}$, both mutants were inviable, whereas ParC1215 cells were inviable at $37^{\circ} \mathrm{C}$. Because of these characteristics, we used only the ParE10 mutant in some experiments. The viability of either mutant did not decrease significantly until $\sim 2 \mathrm{hr}$ at the nonpermissive temperature. To increase the amount of $\left[{ }^{3} \mathrm{H}\right]$ thymidine incorporation, ParC1215 and $\mathrm{C} 600$ strains were made auxotrophic for thymidine by growth in the presence of trimethoprim and high concentrations of thymidine as described (Miller 1972). N51 (gyr $A^{\mathrm{r}}$ ) contains a Ser-83 $\rightarrow$ Leu-83 substitution mutation in the gyrA gene that imparts a 16 -fold resistance to norfloxacin. N51 and its isogenic wild-type parent KL16 (gyr $A^{\text {wt }}$ ) were described previously (Yoshida et al. 1988). CAG12178 contains a transposon at $48.5 \mathrm{~min}$ on the $E$. coli chromosome that encodes tetracycline (Tet) resistance and is adjacent to gyr $A$ (48.3 min) (Singer et al. 1989). All other strains 
Table 1. Bacterial strains

\begin{tabular}{|c|c|c|}
\hline Strain & Genotype & Construction $^{\mathrm{a}}$ or Reference \\
\hline CAG12178 & zei-723::Tn10 & Singer et al. (1989) \\
\hline $\mathrm{C} 600$ & $\mathrm{~F}^{-}$thr-1 leu-6 thi-1 lacY1 supE44 tonA21 & Kato et al. (1988) \\
\hline KL16 & Hfr thi & Yoshida et al. (1988) \\
\hline LZ1 & N51 except zei-723::Tn10 & $\mathrm{P} 1(\mathrm{CAG} 12178) \times \mathrm{N} 51, \mathrm{Tet}^{\mathrm{r}}$ \\
\hline LZ2 & KL16 except zei-723::Tn10 & P1(CAG12178) $\times$ KL16, Tet $^{\mathrm{r}}$ \\
\hline LZ3 & parE10 except $g y r A^{\mathrm{r}} z e i-723:: \operatorname{Tn} 10$ & $\mathrm{P} 1(\mathrm{LZ} 1) \times \operatorname{ParE} 10, \mathrm{Tet}^{\mathrm{r}}$ \\
\hline LZ4 & parE10 except zei-723:: $\operatorname{Tn} 10$ & $\mathrm{P} 1(\mathrm{LZ} 2) \times \operatorname{ParE} 10, \mathrm{Tet}^{\mathrm{r}}$ \\
\hline LZ25 & C600 except thy $A$ & trimethoprim ${ }^{\mathrm{r}}$ \\
\hline LZ26 & parC1215 except thy $A$ & trimethoprim $^{\mathrm{r}}$ \\
\hline N51 & Hfr thi gyrA $A^{\mathbf{r}}$ & Yoshida et al. $(1988)$ \\
\hline ParC1215 & C600 parC1215 met::Tn10 & Kato et al. (1988) \\
\hline ParE10 & W3110 except parE10 & Kato et al. (1990) \\
\hline W3110 & $\mathrm{F}^{-}$ & Kato et al. (1990) \\
\hline
\end{tabular}

${ }^{\mathrm{a} C o n s t r u c t i o n s}$ are shown as chemical used for selection or as donor $\times$ recipient, selection. Abbreviations: (r), Resistant; (Tet), Tetracycline; (P1), source of transducing lysate.

were from this laboratory. For simplicity, we refer to these strains by their relevant genotypes.

\section{Strain construction}

Transductions were carried out with $\mathrm{P} 1_{\text {vira }}$ according to Miller (1972). To construct the par $E^{\text {ts }} g y r A^{\mathrm{r}}$ and $\operatorname{parE}^{\mathrm{ts}} g y r A^{\mathrm{wt}}$ strains, first we transferred the Tet marker from CAG12178 into strains $\mathrm{N} 51$ and KL16. Then the gyr $A^{\mathrm{r}}$ or gyr $A^{\mathrm{wt}}$ gene with its linked Tet marker was transduced into $\operatorname{parC}^{\mathrm{ts}}$, $\operatorname{par}^{\mathrm{ts}}$, or their wildtype strains. The successful transductants were either resistant to both Tet and norfloxacin $\left(g y r A^{\mathrm{r}}\right)$ or resistant to Tet and sensitive to norfloxacin (gyr $\left.A^{\mathrm{wt}}\right)$. Unfortunately, the $\operatorname{par}^{\mathrm{ts}}$ or par $C^{\text {ts }}$ thy $A$ mutants, which were already slow growing, were rendered inviable by the introduction of a drug-resistant mutation in gyrase.

\section{Pulse labeling and pulse chase}

Strains were grown as described (Adams et al. 1992). At a cell density of 70 Klett units, the cells were pelleted for $5 \mathrm{~min}$ at $6000 \mathrm{~g}$ at $4^{\circ} \mathrm{C}$. The pellet was resuspended in $\mathrm{M} 9$ minimal medium supplemented with leucine, thiamine, threonine, and 2 $\mu \mathrm{g} / \mathrm{ml}$ of thymidine. After shaking the cultures at the nonpermissive temperature $\left(43^{\circ} \mathrm{C}\right)$ for $15-30 \mathrm{~min}$, [methyl $\left.{ }^{3} \mathrm{H}\right]$ - or [methyl- $\left.1^{\prime}, 2^{\prime}-{ }^{3} \mathrm{H}\right)$ thymidine $(50 \mu \mathrm{l} / \mathrm{ml}$ of cells $)$ was added. The specific activity of the former was $82-85 \mathrm{Ci} / \mathrm{mmole}(1 \mathrm{mCi} / \mathrm{ml})$; the latter was $110 \mathrm{Ci} / \mathrm{mmole}(1 \mathrm{mCi} / \mathrm{ml})$.

$\left[{ }^{3} \mathrm{H}\right]$ thymidine incorporation into total DNA was linear for $\sim 5 \mathrm{~min}$ at $43^{\circ} \mathrm{C}$ and then plateaued in all strains. The rate of incorporation into chromosomal or plasmid DNA was the same at the nonpermissive temperature for all strains from 0 to 120 min. Therefore, at least initially, neither chromosomal nor plasmid DNA replication is affected at the nonpermissive temperature for the topo IV mutants. One to $5 \mathrm{~min}$ after addition of label, cells were lysed and pBR322 plasmids separated selectively from chromosomal DNA by the alkaline lysis method (Sambrook et al. 1989). Alternative methods of plasmid isolation were also tried: (1) triton lysis (Clewell and Helinski 1970), (2) boiling, (3) rapid freeze/boiling, or (4) rapid stop (Okazaki 1974). Results were similar with all methods, but other methods did not separate completely the chromosomal from the plasmid DNA and led to increased background. In the pulse-chase experiments, the cells were labeled for $1-3 \mathrm{~min}$ and chased for various times with $4 \mathrm{mg} / \mathrm{ml}$ (final concentration) of thymidine. When norfloxacin was used, it was added with the chase.

\section{Decatenation rate calculation}

To model the pulse experiments, we assumed that all replicated plasmids proceed through catenated intermediates, and we treated decatenation as a one-step reaction, from catenane to free circles. We also supposed that all newly synthesized DNA is labeled. To simplify the analysis of the model we considered a time interval that is small in comparison with the cell doubling time. As a result, we could neglect the replication of labeled monomers and the decatenation of cold catenanes. Thus, we have only two variables in the system, the number of labeled monomers $N_{1}$ and the number of labeled catenanes $N_{2}$. There are also some unlabeled circles, $N_{0}$, but this is a constant. Thus the system dynamics can be described by the equations:

$$
\begin{aligned}
& \frac{d N_{1}}{d t}=2 k_{d} N_{2} \\
& \frac{d N_{2}}{d t}=k_{r} N_{0}-k_{d} N_{2}
\end{aligned}
$$

where $k_{d}$ and $k_{r}$ are decatenation and replication rate constants, and $t$ is time. The solution of this system is

$$
\begin{aligned}
& N_{1}=2 N_{0} k_{r} t-2 N_{0} \frac{k_{r}}{k_{d}}\left[1-\exp \left(-k_{d} t\right)\right] \\
& N_{2}=N_{0} \frac{k_{r}}{k_{d}}\left[1-\exp \left(-k_{d} t\right)\right]
\end{aligned}
$$

Note that the intensity of the monomer and catenane gel bands will be proportional to $N_{1}$ and $2 N_{2}$. For the relative intensity of catenane bands we have

$$
\frac{2 N_{2}}{N_{1}+2 N_{2}}=\frac{1-\exp \left(-k_{d} t\right)}{k_{d} t}
$$

which allows us to calculate $k_{d}$. 


\section{Gel electrophoresis, fluorography, and quantitation}

Plasmid DNA was run on high-resolution agarose gels as described (Sundin and Varshavsky 1981; Adams et al. 1992). Gels were soaked in $\mathrm{En}^{3}$ Hance for 3-4 hr until translucent and in water for 45-60 min until opaque. Gels were flattened onto Whatman $3 \mathrm{MM}$ paper for $\sim 1 \mathrm{hr}$ to remove most of the moisture and then dried on a gel drier (Hoefer). Preflashed Kodak $\mathrm{X}$-OMAT film was placed directly onto the dried gel and exposed for 1-60 days at $-70^{\circ} \mathrm{C}$. Gel bands were quantified by soft laser scanning densitometry (LKB) of autoradiographs exposed for varying amounts of time such that bands of interest were within the linear range of the film.

\section{Acknowledgments}

We thank A.V. Vologodskii for help in the calculations. We also thank C.A. Gross, H. Ikeda, J. Kato, S. Nakamura, and H. Suzuki for providing mutant strains and S.J. Sandler for $\mathrm{Pl}_{\text {vira }}$. We are grateful to K. Collins, M. Dunaway, N. Osheroff, S.J. Sandler, R.D. Schrock, and members of the laboratory for critical reading of this manuscript and M. Gonzalez, N.P. Higgins, and K.N. Kreuzer for helpful discussions. This work was supported by National Institutes of Health (NIH) grant GM31657. E.L.Z. was supported by NIH postdoctoral fellowship GM14574 and is a Special Fellow of the Leukemia Society of America.

The publication costs of this article were defrayed in part by payment of page charges. This article must therefore be hereby marked "advertisement" in accordance with 18 USC section 1734 solely to indicate this fact.

\section{References}

Adams, D.E., E.M. Shekhtman, E.L. Zechiedrich, M.B. Schmid, and N.R. Cozzarelli. 1992. The role of topoisomerase IV in partitioning bacterial replicons and the structure of catenated intermediates in DNA replication. Cell 71: 277-288.

Andoh, T., H. Ikeda, and M. Oguro. 1993. Molecular biology of DNA topoisomerases and its application to chemotherapy. In Proceedings of the International Symposium on DNA Topoisomerases in Chemotherapy. CRC Press, Boca Raton, FL.

Baker, T.A., K. Sekimizu, B.E. Funnell, and A. Komberg. 1986. Extensive unwinding of the plasmid template during staged enzymatic initiation of DNA replication from the origin of the Escherichia coli chromosome. Cell 45: 53-64.

Bliska, J.B. and N.R. Cozzarelli. 1987. Use of site-specific recombination as a probe of DNA structure and metabolism in vivo. J. Mol. Biol. 194: 205-218.

Champoux, J.J. and M.D. Been. 1980. Topoisomerases and the swivel problem. In Mechanistic studies of DNA replication and genetic recombination: ICN-UCLA symposia on molecular and cellular biology (ed. B. Alberts), pp. 809-815. Academic Press, New York, N.Y.

Clewell, D.B. and D.R. Helinski. 1970. Properties of a supercoiled deoxyribonucleic acid-protein relaxation complex and strand specificity of the relaxation event. Biochemistry 9: $4428-4440$.

Cozzarelli, N.R. 1992. Evolution of DNA topology: Implications for its biological roles. Proc. Symp. Appl. Math. 45: 116.

DiGate, R.J. and K.J. Marians. 1988. Identification of a potent decatenating enzyme from Escherichia coli. I. Biol. Chem. 263: 13366-13373.

DiNardo, S., K.A. Voelkel, R. Sternglanz, A.E. Reynolds, and A.
Wright. 1982. Escherichia coli DNA topoisomerase I mutants have compensatory mutations in DNA gyrase genes. Cell 31: 43-51.

Drlica, K. 1987. The nucleoid. In Escherichia coli and Salmonella typhimurium (ed. F.C. Neidhardt), pp. 91-103. American Society for Microbiology, Washington, D.C.

Fields-Berry, S.C. and M.L. DePamphilis. 1989. Sequences that promote formation of catenated intertwines during termination of DNA replication. Nucleic Acids Res. 17: 3261-3273.

Filutowicz, M. 1980. Requirement of DNA gyrase for the initiation of chromosomal replication in Escherichia coli $\mathrm{K}-12$. Mol. \& Gen. Genet. 177: 301-309

Filutowicz, M. and P. Jonczyk. 1983. The gyrB gene product functions in both initiation and chain polymerization of Escherichia coli chromosome replication: Suppression of the initiation deficiency in $\mathrm{gyr}^{\mathrm{ts}}$ mutants by a class of $r p o B$ mutations. Mol. \& Gen. Genet. 191: 282-287.

Hiasa, H., R. Digate, and K. Marians. 1994. Decatenating activity of Escherichia coli DNA gyrase and topoisomerase- 1 and topoisomerase-III during oriC and pBR322 DNA replication in vitro. J. Biol. Chem. 269: 2093-2099.

Hoshino, K., A. Ketamura, I. Morrissey, K. Sato, J.-i. Kato, and H. Ikeda. 1994. Comparison of inhibition of Escherichia coli topoisomerase IV by quinolones with DNA gyrase inhibition. Antimicrob. Agents Chemother. 38: 2623-2627.

Kato, J.-i., Y. Nishimura, M. Yamada, H. Suzuki, and Y. Hirota. 1988. Gene organization in the region containing a new gene involved in chromosome partition in Escherichia coli. J. Bacteriol. 170: 3967-3977.

Kato, J.-i., Y. Nishimura, R. Imamura, H. Niki, S. Hiraga, and H. Susuki. 1990. New topoisomerase essential for chromosome segregation in Escherichia coli. Cell 63: 393-404.

Kato, J.-i., H. Suzuki, and H. Ikeda. 1992. Purification and characterization of DNA topoisomerase IV in Escherichia coli. J. Biol. Chem. 267: 25676-25684.

Khodursky, A., E.L. Zechiedrich, and N.R. Cozzarelli. 1995. Topoisomerase IV is a target of quinolones in Escherichia coli. Proc. Natl. Acad. Sci. 92: (in press).

Kirchhausen, T., J.C. Wang, and S.C. Harrison. 1985. DNA gyrase and its complexes with DNA: Direct observation by electron microscopy. Cell 41: 933-943.

Kreuzer, K., and N. Cozzarelli. 1979. Escherichia coli mutants thermosensitive for DNA gyrase subunit A: Effects on DNA replication, transcription, and bacteriophage growth. I. Bacteriol. 140: 424-435.

. 1980. Formation and resolution of DNA catenanes by DNA gyrase. Cell 20: 245-254.

Luttinger, A.L., A.L. Springer, and M.B. Schmid. 1991. A cluster of genes that affects nucleoid segregation in Salmonella typhimurium. New Biol. 3: 687-697.

Marians, K.J. 1987. DNA gyrase-catalyzed decatenation of multiply linked DNA dimers. J. Biol. Chem. 262: 10362-10368.

Miller, J.H. 1972. Experiments in genetics. Cold Spring Harbor Laboratory, Cold Spring Harbor, New York.

Okazaki, R. 1974. Methods in molecular biology (ed. R.B. Wickner), Dekker, New York, NY.

Orr, E., N.F. Fairweather, I.B. Holland, and R.H. Pritchard. 1979. Isolation and characterization of a strain carrying a conditional lethal mutation in the cou gene of Escherichia coli K-12. Mol. \& Gen. Genet 177: 103-112

Osheroff, N., E.L. Zechiedrich, and K.C. Gale. 1991. Catalytic function of DNA topoisomerase II. BioEssays 13: 269-273.

Peng, H. and K.J. Marians. 1993a. Escherichia coli topoisomerase IV; purification, characterization, subunit structure, and subunit interactions. J. Biol. Chem. 268: 2448124490 . 
1993b. Decatenation activity of topoisomerase IV during oriC and pBR322 replication in vitro. Proc. Natl. Acad. Sci. 90: 8571-8575.

1995. The interaction of Escherichia coli topoisomerase IV with DNA. I. Biol. Chem. 270: (in press).

Pohl, W.F. and G.W. Roberts. 1978. Topological considerations in the theory of replication of DNA. J. Math. Biol. 6: 383402.

Raji, A., D.J. Zabel, C.S. Laufer, and R.E. Depew. 1985. Genetic analysis of mutations that compensate for loss of Escherichia coli DNA topoisomerase I. J. Bacteriol. 162: 1173-1179.

Reece, R.J. and A. Maxwell. 1991. DNA gyrase: Structure and function. Crit. Rev. Biochem. Mol. Biol. 26: 335-375.

Roca, J. and J.C. Wang. 1992. The capture of a DNA double helix by an ATP-dependent protein clamp: A key step in DNA transport by topo II DNA topoisomerases. Cell 71: 833-840.

. 1994. DNA transport by a type II DNA topoisomeraseEvidence in favor of a two-gate mechanism. Cell 77: 609616.

Sambrook, J., E.F. Fritsch, and T. Maniatis. 1989. Molecular cloning: A laboratory manual. Cold Spring Harbor Laboratory Press, Cold Spring Harbor, New York.

Schmid, M.B. 1990. A locus affecting nucleoid segregation in Salmonella typhimurium. I. Bacteriol. 172: 5416-5424.

Singer, M., T.A. Baker, G. Schnitzler, S.M. Deischel, M. Goel, W. Dove, K.J. Jaacks, A.D. Grossman, J.W. Erikson, and C.A. Gross. 1989. A collection of strains containing genetically linked alternating antibiotic resistance elements for genetic mapping of Escherichia coli. Microbiol. Rev. 53: 1-24.

Springer, A.L. and M.B. Schmid. 1993. Molecular characterization of the Salmonella typhimurium parE gene. Nucleic Acids Res. 21: 1805-1809.

Steck, T.R. and K. Drlica. 1984. Bacterial chromosome segregation: Evidence for DNA gyrase involvement in decatenation. Cell 36: 1081-1088.

Sundin, O. and A. Varshavsky. 1981. Arrest of segregation leads to accumulation of highly intertwined catenated dimers: Dissection of final stages of SV40 DNA replication. Cell 25: 659-669.

Ullsperger, C.J., A.V. Vologodskii, and N.R. Cozzarelli. 1995. Unlinking of DNA by topoisomerases during DNA replication. In Nucleic acids and molecular biology (ed. D.M.J. Lilley and F. Eckstein), vol. 9, pp. 115-142. Springer-Verlag, Berlin, Germany.

Vologodskii, A.V. and N.R. Cozzarelli. 1993. Monte Carlo analysis of the conformation of DNA catenanes. I. Mol. Biol. 232: 1130-1140.

Wang, J.C. 1991. DNA topoisomerases: Why so many? J. Biol. Chem. 266: 6659-6662.

Wasserman, S.A. and N.R. Cozzarelli. 1986. Biochemical topology: Applications to DNA recombination and replication. Science 232: 951-960.

Watson, J.D. and F.H.C. Crick. 1953. The structure of DNA. Nature 171: 123-131.

Yoshida, H., T. Kojima, J.-i. Yamagishi, and S. Nakamura. 1988. Quinolone-resistant mutations of the gyrA gene of Escherichia coli. Mol. \& Gen. Genet. 211: 1-7.

Zechiedrich, E.L. and N. Osheroff. 1990. Eukaryotic topoisomerases recognize nucleic acid topology by preferentially interacting with DNA crossovers. EMBO I. 9: 4555-62. 


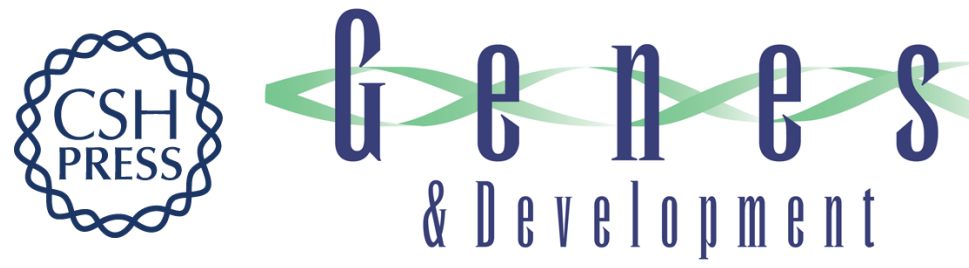

\section{Roles of topoisomerase IV and DNA gyrase in DNA unlinking during replication in Escherichia coli.}

E L Zechiedrich and N R Cozzarelli

Genes Dev. 1995, 9:

Access the most recent version at doi:10.1101/gad.9.22.2859

References This article cites 40 articles, 14 of which can be accessed free at:

http://genesdev.cshlp.org/content/9/22/2859.full.html\#ref-list-1

License

Email Alerting

Service

Receive free email alerts when new articles cite this article - sign up in the box at the top right corner of the article or click here.

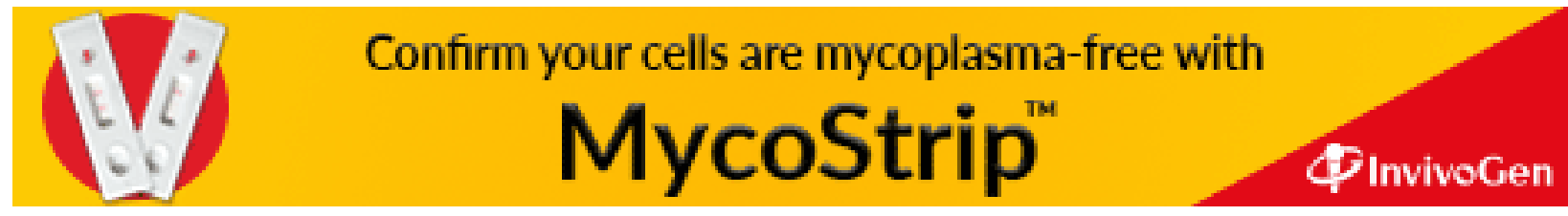

